Research Article

\title{
Experimental Approach to Active Mounts Using Electromagnetic Actuator and Rubber with Consideration of Shock Resistance for Naval Shipboard Equipment
}

\author{
Yun-ho Shin $\mathbb{D}^{1},{ }^{1}$ Seok-jun Moon, ${ }^{1}$ Woo-jin Jung, ${ }^{2}$ and Soo-ryong Bae ${ }^{2}$ \\ ${ }^{1}$ Department of System Dynamics, Korea Institute of Machinery and Materials, 156 Gajeongbuk-ro, Yuseong-gu, \\ Daejeon 305-343, Republic of Korea \\ ${ }^{2}$ Agency for Defense Development, Seoul, Republic of Korea \\ Correspondence should be addressed to Yun-ho Shin; shinyh77@kimm.re.kr
}

Received 23 February 2019; Accepted 2 April 2019; Published 16 April 2019

Guest Editor: María J. Gómez-García

Copyright (C) 2019 Yun-ho Shin et al. This is an open access article distributed under the Creative Commons Attribution License, which permits unrestricted use, distribution, and reproduction in any medium, provided the original work is properly cited.

There is demand for stringent vibration isolation within machine installations in order to achieve maximum performance or to satisfy otherwise extreme criteria, particularly, when there is a strong source of vibration such as a motor pump. It is frequently necessary to prevent the transmission of these vibrations to other parts of the system for passenger comfort in vehicles, ships, trains, etc., or for the protection of delicate electronic equipment. In the defense sector, the need for equipment which is better at avoiding detection has led researchers to focus more on improving vibration isolation. In this paper, an active mount combined with a passive rubber mount and an electromagnetic actuator is proposed and examined for use in naval shipboard equipment. The electromagnetic actuator is suggested for improving performance and overcoming its inherent limitations which are caused by the friction between the magnet and coil. The design specifications of an active mount, such as required force, displacement, and frequency characteristics, are identified for the self-excited pump system, and then an electromagnetic actuator active mount is redesigned with considering the shape of the passive rubber mount and shock resistance. The performance was examined on the single active mount using an external exciter, which could be simplified as two-degree-of-freedom system, and also confirmed experimentally on an active mount system with four mounts using a motor system. From the results of applying the proposed electromagnetic active mount, a vibration reduction of about $20 \mathrm{~dB}$ for the motor equipment was observed for the excited frequency components of $1,600 \mathrm{rpm}$ and its two harmonic components.

\section{Introduction}

Vibration isolation is an important requirement throughout many areas of engineering, particularly when there is a strong source of vibration such as a motor pump. It is frequently necessary to prevent the transmission of these vibrations to other parts of the system for reasons such as passenger comfort in vehicles, ships, trains, etc., or for the protection of delicate electronic equipment [1]. In the defense sector, the need for equipment which can better avoid detection has led researchers to focus more on improving vibration isolation [2]. Passive vibration isolators separate objects of interest from external vibrations without using power or a control system. Compared with active isolators that use active or semiactive technologies, passive vibration isolators are suitable for applications in which compactness, cost, and reliability are primary concerns [3]. However, the high performance vibration isolation that is required for more sensitive applications, and in defense equipment, necessitates active isolation technology. Active isolators can perform at a higher level than passive isolators through the incorporation of an active component. Collette et al. have reviewed several patented developments in the field of active vibration isolation [4]. They demonstrated that active suspension does not suffer from the two fundamental trade-offs between the settling time caused by the 
direct excitation of payload and the transmissibility by the base excitation through the isolator which are inherently given to passive suspension design. Then, the main active strategies were presented and compared using singledegree-of-freedom models. Cho et al. have focused on configurations of active mounts which are combined with passive and active components [5]. The seven configurations are presented according to the connection of an active element to a passive element. Shin et al. [2] have proposed an active mount that uses an electromagnetic actuator to reduce vibrations transmitted from naval shipboard equipment to the structure of the ship's hull. The active mount combines a proven rubber mount and a moving magnetic-based electromagnetic actuator. It is ideal for reducing vibrations at a low frequency range (under $300 \mathrm{~Hz}$ ) and has fail-safe capabilities that protect the equipment at the top of the mount from external shock. Kaal et al. [6] have presented the development, simulation, and experimental investigation for a proof of concept of active vibration isolation with dielectric elastomers. It can support large masses because it is capable of withstanding compressive forces without stability drawbacks. The actuator design can easily be adjusted to specific requirements by changing the size of the active area or the number of layers. Lee et al. [7] have presented the design, simulation, and manipulation of a 6-axis hybrid vibration isolation system. This vibration isolation system is composed of four spiral metal springs for passive isolation and eight voice coil motors for active isolation.

This paper discusses an active mount which combines a passive rubber mount and an electromagnetic actuator that can be applied to naval shipboard equipment. While it is similar with the actuator in reference [2], this electromagnetic actuator is modified for improved performance and to overcome its inherent limitations. First, the design specifications for active mounts, such as required force, displacement, and frequency characteristics, are identified for the self-excited pump system. Second, an electromagnetic actuator active mount is designed, over and over, with consideration for the shape of the passive rubber mount and for shock resistance. Third, the performance of the single active mount is examined experimentally by using an external exciter. Finally, the control performance is also confirmed experimentally on an active mount system with four mounts using a motor system.

\section{Design of an Active Mount with Consideration for Shock Resistance}

\subsection{Required Force to Control the Objective Pump-Motor} System. A schematic diagram of the target system is described in Figure 1 of this study. Based on basic information and the measurements of the target system (pump-motor and piping systems), the required control force was calculated. After applying only the resilient mount corresponding to the passive part of the active mount to the bottom of the pump motor, the vibrations were measured and analyzed. At the bottom of the pump, four passive mounts are installed (locations 1 to 4 ), and the average of the measured accelerations at each installed location is obtained to calculate the required control force to select or design the proper actuator. Figure 2 shows the results of vertical acceleration, when the instrument's rotational speed was set to $1,600 \mathrm{rpm}$ in each installation location, in terms of $1 / 3$ octave band and compares them with the vibration tolerance specification (MIL-STD-740) [8]. It is possible to confirm that the frequency range of interest corresponds with the configured purpose of the active mount, and high frequency vibration reductions can be observed through the passive mount.

It is relatively difficult to estimate the excitation force of the system by using the measured vibration signals for the target system. However, by calculating the force transmitted to the hull or other equipment when the specifications of the viscoelastic mount, such as stiffness and damping, are known, the force can be estimated using this simple calculation. The force transmitted from the equipment to the hull is calculated using equation (1) after measuring absolute acceleration (or velocity, displacement) information at the top and bottom of the mount.

$$
F_{T}=c_{\mathrm{r}}\left(\dot{x}_{\mathrm{e}}-\dot{x}_{\mathrm{b}}\right)-k_{\mathrm{r}}\left(x_{\mathrm{e}}-x_{\mathrm{b}}\right)
$$

In equation (1), $k$ and $c$ denote the stiffness and damping coefficients, respectively, and subscripts e and b denote the top and bottom of mount, respectively. The specifications of stiffness and damping, used for calculating the transmitted force, are $5.27 \times 10^{5} \mathrm{~N} / \mathrm{m}$ and $1.58 \times 10^{3} \mathrm{Ns} / \mathrm{m}$.

The required control force calculated from the relevant frequency components and the averaged values obtained from the viscoelastic mounts (locations 1 to 4 ) at the bottom of the pump system are described in Table 1. The frequency components that differ by more than $20 \mathrm{~dB}$ from the maximum value of the measured transmitted force are regarded as sufficiently small and excluded from the frequency component to be controlled. In order to conservatively design the actuator, the maximum required operating force of the actuator is set to $120 \mathrm{~N}$ based on the transmitted force in the time domain, and the maximum displacement is $\pm 1 \mathrm{~mm}$. It is how the target performance in designing the electromagnetic actuator together with the constraints on space is designated.

2.2. Electromagnetic Actuator Design of Hybrid Mount considering Shock Resistance: Phase I. In previous research [2], the design of the electromagnetic actuator was based on a three-level concept, as shown in Figure 3, which took into consideration the type of moving coil and the type of moving permanent magnet. In addition to the design proposed previously, the detailed proposal and the conceptual design are presented in the additional, detailed design plan.

The results of determining the detailed specifications for production are as follows: the ferro-metal for the electromagnetic actuator is SS400 ferrite chrome steel and the permanent magnet is a $\mathrm{N} 42 \mathrm{H}$ sintered neodymium zinc boron magnet. Because permanent magnets are difficult to 


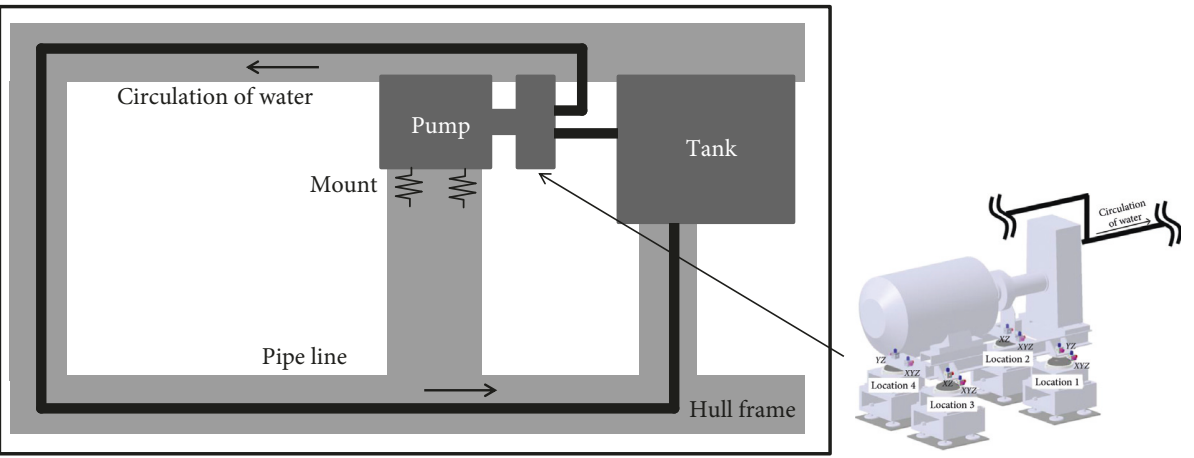

FIGURE 1: Overall schematic of target system.

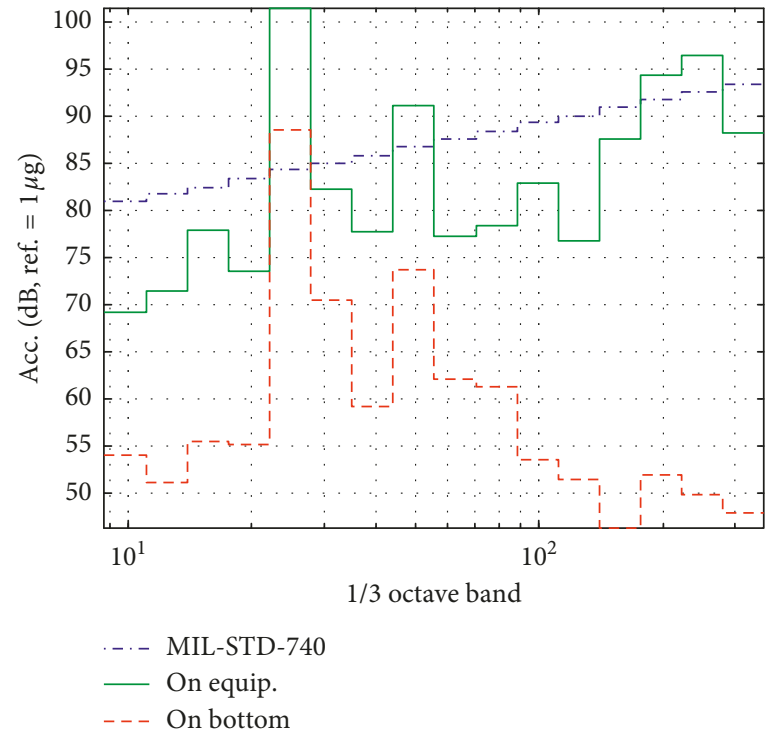

(a)

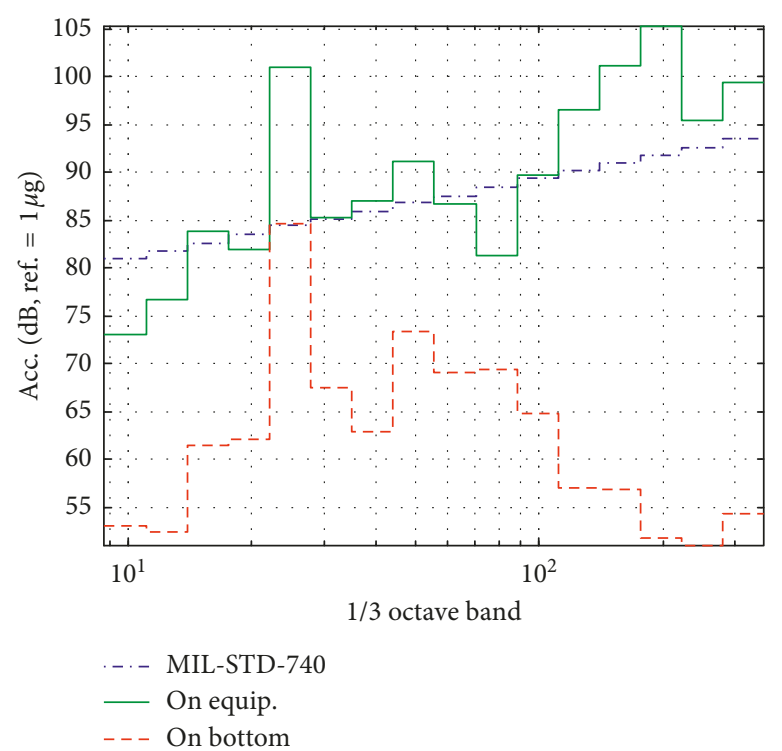

(c)

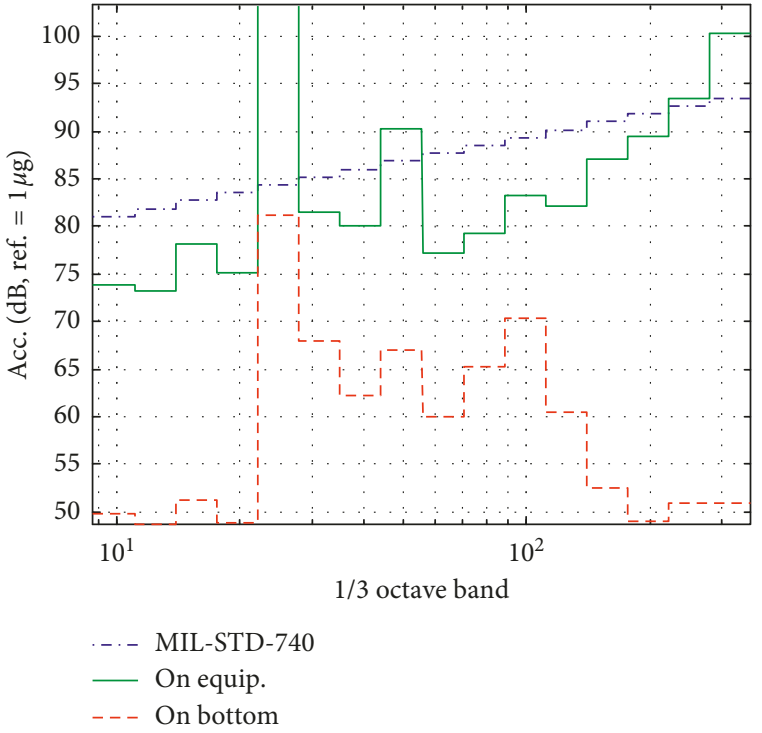

(b)

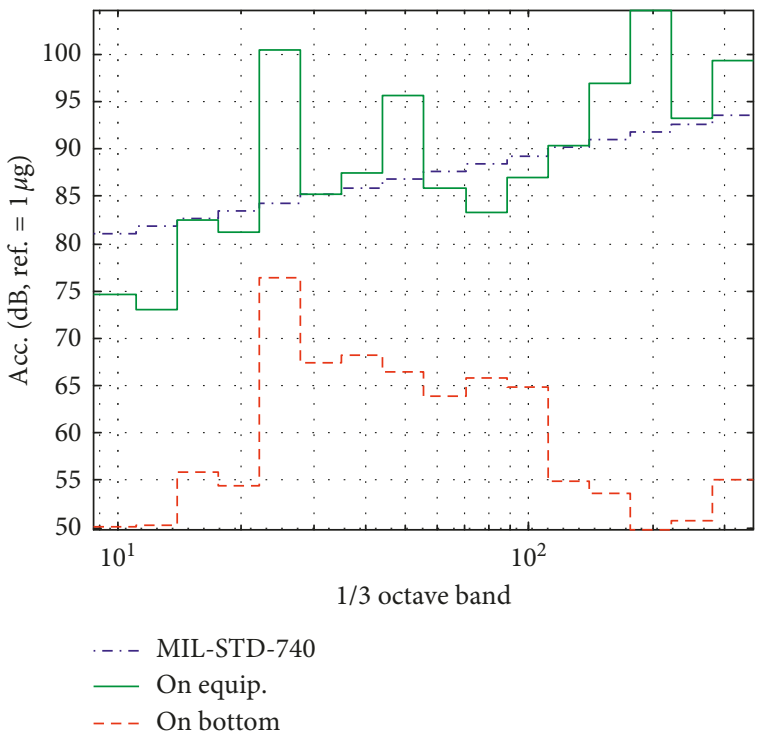

(d)

Figure 2: Acceleration signals at supported location: 1/3 octave scale. (a) Location 1. (b) Location 2. (c) Location 3. (d) Location 4. 
TABLE 1: Required design specification of the electromagnetic actuator.

\begin{tabular}{lr}
\hline Domain & Required force or displacement \\
\hline \multirow{2}{*}{ Frequency domain } & $41.5 \mathrm{~N}_{\text {peak } @ 26.5 \mathrm{~Hz}}$ \\
\hline \multirow{2}{*}{ Time domain } & $3.3 \mathrm{~N}_{\text {peak }} @ 53.3 \mathrm{~Hz}$ \\
\hline
\end{tabular}

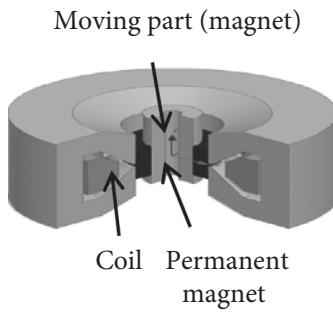

(a)

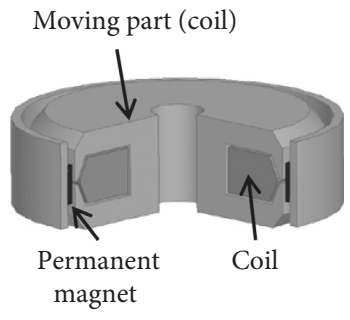

(b)

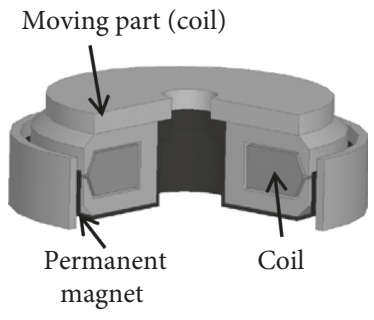

(c)

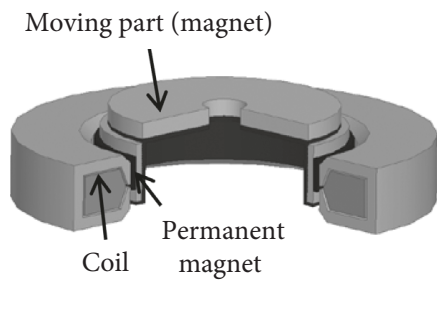

(d)

Figure 3: Design of electromagnetic actuator. (a) $1^{\text {st }}$ concept design. (b) $2^{\text {nd }}$ concept design. (c) Detailed design-I. (d) Detailed design-II.

produce in one circular form, they are made in a toric shape by attaching pieces in a circumferential direction. The coil used in this study is self-bound type which suffers over time from the partial melting of the sheath covering it, once the current begins to run through it. The diameter of coil material, copper, is determined by $1.3 \mathrm{~mm}$ (AWG \#16), and the coil is wrapped with 270 turns, respectively. When the current flows through, the coil is peeled off and wound. The materials of the joints used to fix the mover and the stator and the passive mounts attached to the actuator are made of stainless steel to reduce magnetic flux leakage during control; Figure 4 shows the schematic drawings of the prototype including the mover, the stator, and the viscoelastic passive mount for the electromagnetic actuators types I and II which are described in Table 2. The final assembly of the passive mount element and the assembled electromagnetic actuator is shown in Figure 5 along with the coil and the permanent magnet parts.

The designed gap between the mover and the stator of the actuator for the horizontal direction was $2 \mathrm{~mm}$. However, the gap was relatively small and difficult to be realized because when the mount is installed, a force acts between the permanent magnet and the metal forming a magnetic pole and that makes it difficult to align the center of gravity. This is because there is a high possibility of adhesion between the metal and the mover after the center is installed, and the viscoelastic material, being in a thin layer $(1.8 \mathrm{~mm})$, is used in the pore to maintain the pore distance. The measured resistance value of the manufactured electromagnetic actuator $\mathrm{I}$ is $1.1 \Omega$, and it shows a $6.4 \%$ error according to the analytical results $(1.17 \Omega)$ of the commercial program used in the electromagnetic field analysis of this study, and the resistance measurement results of the electromagnetic actuator II is $2.1 \Omega$ according to the results of the commercial program's analysis $(2.23 \Omega$ ) with an error of $6.2 \%$. The analysis results for both actuators I and II including resistances by ANSYS Maxwell are described in Table 3.
The block diagram of experimental configurations required for the performance evaluation of the manufactured hybrid mount is shown in Figure 6. It is the equipment configuration to measure the force generated when the current is applied to the hybrid mount; the overall equipment configuration is shown in Figure 7 , and the test conditions are described in Table 4. The satisfaction of the requirements for each actuator, based on measurement results, is also described in Table 5.

Based on the results of the performance tests of the two proposed electromagnetic actuator designs, it was confirmed that the required actuating force was satisfied. However, it was also observed that the actuator is likely to cause friction when the actuator is not made ideally (eccentricity 0 ) due to the force applied in the horizontal direction as shown in Figure 7. In order to compensate for that, the modified electromagnetic actuator design is proposed in the next section.

\subsection{Electromagnetic Actuator Design of Hybrid Mount with} Consideration for Shock Resistance: Phase II. The new design of the actuator is being proposed in order to eliminate the harmonics present at low frequencies, below $50 \mathrm{~Hz}$, caused due to the electromagnetic actuator friction mentioned before. The following are the specific points related to actuator design modifications:

(1) The permanent magnets and the metal for forming the magnetic path are integrated so that no attractive force acts between the magnet and the metal

(2) The coil part is designed to be connected with the hull so that the magnet part and the coil part do not pull out, even if eccentricity exists

(3) Modifying the design so that the mover can move up and down without contact in order to secure shock resistance 

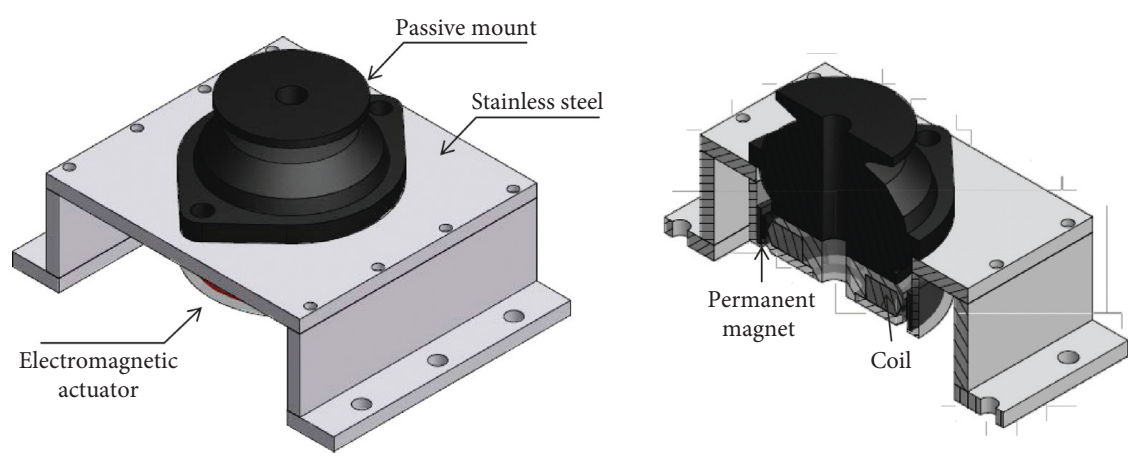

(a)
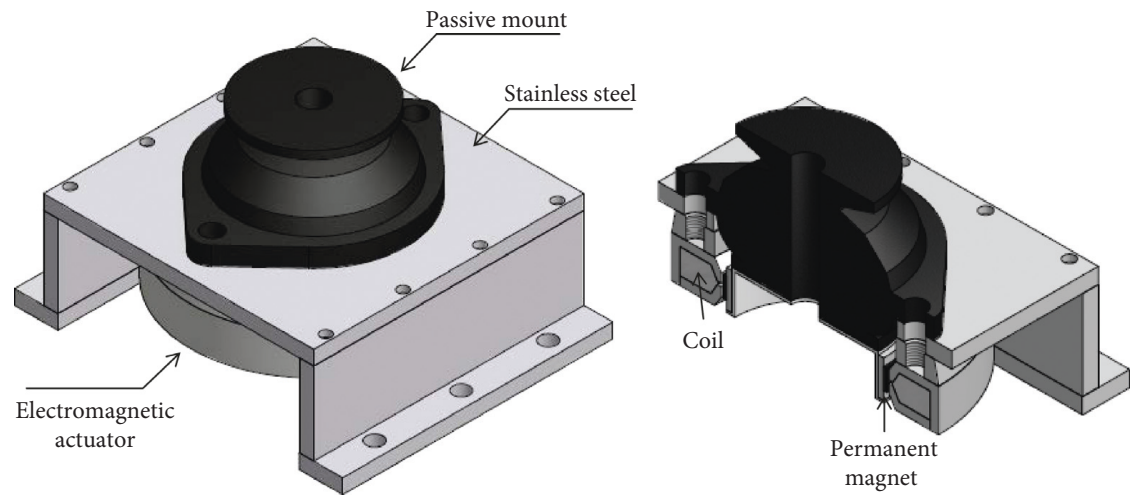

(b)

Figure 4: Schematic drawings for detailed design. (a) Detailed design-I. (b) Detailed design-II.

TABLE 2: Details of suggested actuator.

\begin{tabular}{lcr}
\hline & Detailed design-I & Detailed design-II \\
\hline Electrical gap & $5 \mathrm{~mm}$ & $5 \mathrm{~mm}$ \\
Mechanical gap & $2 \mathrm{~mm}$ & $2 \mathrm{~mm}$ \\
Coil specification & $\varnothing 1.3 \mathrm{~mm} \times 270$ turns & $\varnothing 1.3 \mathrm{~mm} \times 270$ turns \\
Weight & Abt. $6.5 \mathrm{~kg}$ & Abt. $10 \mathrm{~kg}$ \\
\hline
\end{tabular}

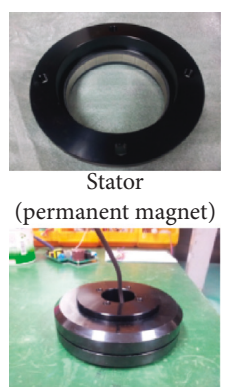

Mover (coil)

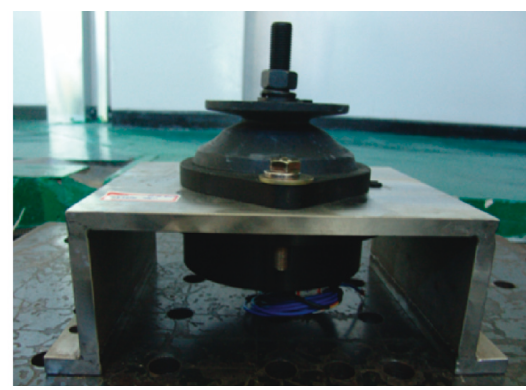

Assembly of hybird mount-I

(a)

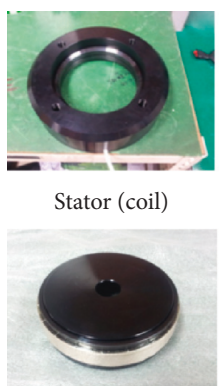

Mover (permanent magnet)

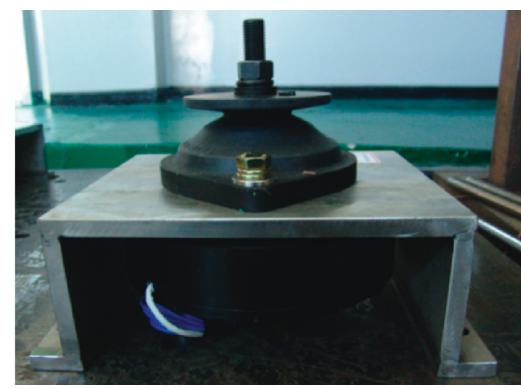

Assembly of hybird mount-II

(b)

FIgURE 5: Electromagnetic active mount. (a) Detailed design-I. (b) Detailed design-II.

Considering the maximum deflection in the compression-tension direction (about $50 \mathrm{~mm}$ ) based on the results of the impact test run according to the procedures of MIL-S-901D [9] for the hybrid mount hand part (6K900) shown in Figure 8, the design was carried out in order to solve the friction problem mentioned above, and the final suggested design is shown in Figure 9. The hammer of $3,000 \mathrm{lb}$ is impacted to the mount-equipped naval 
TABLE 3: Analysis results of suggested actuator.

\begin{tabular}{lcc}
\hline & Detailed design-I & Detailed design-II \\
\hline Resistance & $1.17 \Omega$ & $2.33 \Omega$ \\
Inductance & $0.20 \mathrm{H}$ & $0.22 \mathrm{H}$ \\
Input voltage & $150 \mathrm{~V}$ & $150 \mathrm{~V}$ \\
Time constant & $0.17 \mathrm{sec}$ & $0.09 \mathrm{sec}$ \\
\hline
\end{tabular}

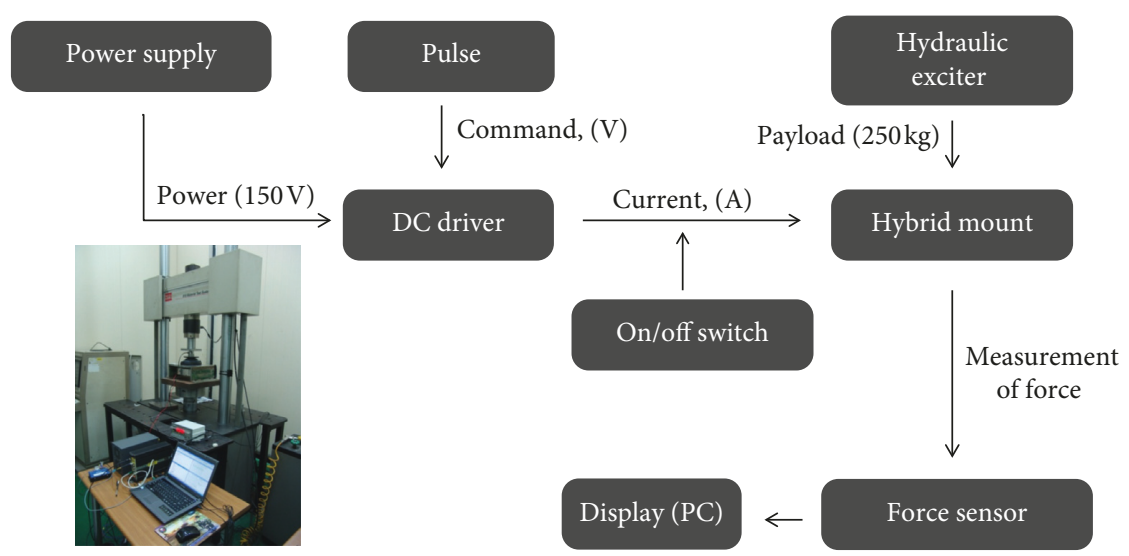

FIGURE 6: Configuration of blocking force measurements [2].

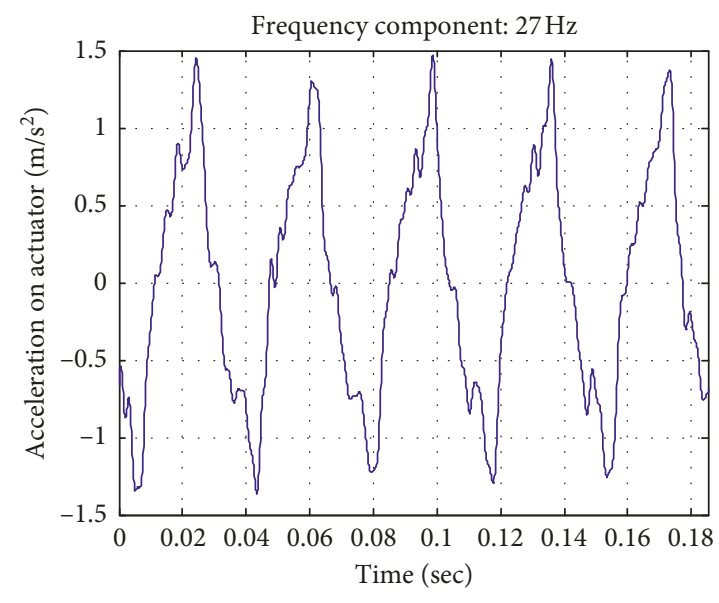

(a)

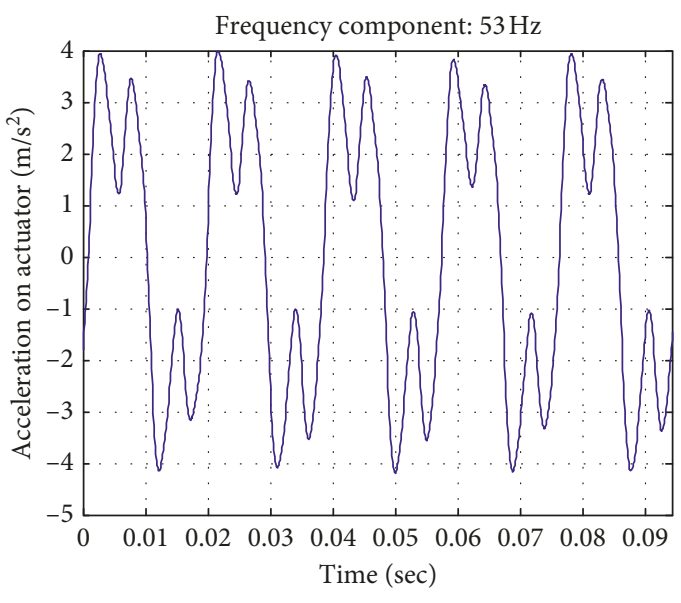

(b)

FiguRE 7: Acceleration of suggested actuator for command input voltage of pure sine. (a) $27 \mathrm{~Hz}$. (b) $53 \mathrm{~Hz}$.

TABLE 4: Experiment condition for measurement of blocking force.

\begin{tabular}{lccc}
\hline Frequency range & Step size of frequency & Input current & Remarks \\
\hline $10-100 \mathrm{~Hz}$ & $\Delta 10 \mathrm{~Hz}$ & $1 \mathrm{~A}_{\text {Peak }}, 2 \mathrm{~A}_{\text {Peak }}$ & Additional measurement at $26.7 \mathrm{~Hz}, 53.4 \mathrm{~Hz}$ \\
$100-300 \mathrm{~Hz}$ & $\Delta 25 \mathrm{~Hz}$ & $1 \mathrm{~A}_{\text {Peak }}, 2 \mathrm{~A}_{\text {Peak }}$ & \\
\hline
\end{tabular}

shipboard equipment, and it must be able to withstand the impact imposed by the weight of the hammer for given height in reference [9]. To consider the impact, $10 \mathrm{~mm}$ is determined as the vertical gap between coil and magnet, and the integrity was confirmed from the test for the final design.
The electromagnetic field analysis was performed using a commercial electromagnetic analysis program to calculate the force and the electromagnetic characteristic parameters for the improved design. The detailed design specifications are described in Table 6 , and the modeling results and the analysis results are shown in Figure 10. The parameters of 
TABLE 5: Measurement results of blocking force compared with required force.

\begin{tabular}{lccc}
\hline Experimental setup & Required & Detailed design-I & Detailed design-II \\
\hline @ $26.5 \mathrm{~Hz}$ & $41.5 \mathrm{~N}_{\text {peak }}$ & $930 \mathrm{~N}_{\text {peak }}$ & $405 \mathrm{~N}_{\text {peak }}$ \\
@ $53.3 \mathrm{~Hz}$ & $3.3 \mathrm{~N}_{\text {peak }}$ & $548 \mathrm{~N}_{\text {peak }}$ & $124 \mathrm{~N}_{\text {peak }}$ \\
Max. value & $120 \mathrm{~N}_{\text {peak }}$ & $1,200 \mathrm{~N}_{\text {peak }}$ & $900 \mathrm{~N}_{\text {peak }}$ \\
\hline
\end{tabular}

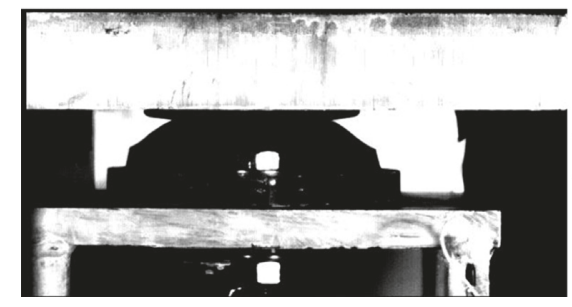

(a)

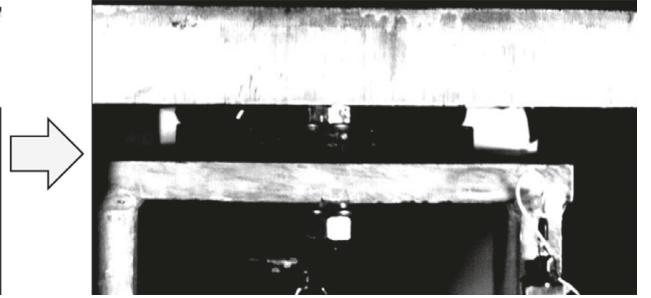

(b)

FIGURE 8: Maximum deflection of passive rubber mount applying required shock based on MIL-S-901D. (a) Equilibrium state. (b) Maximum deflection.

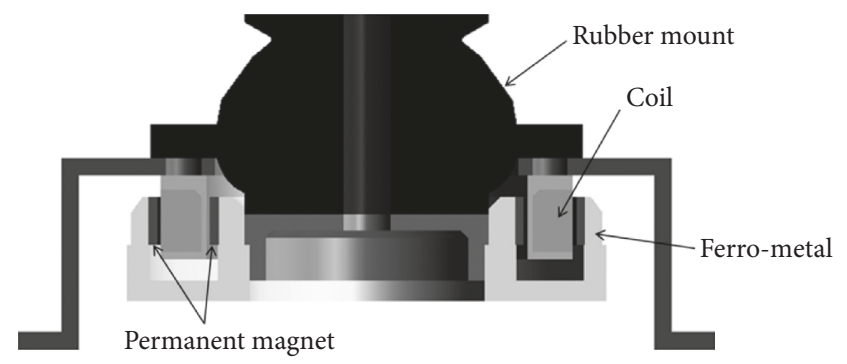

(a)

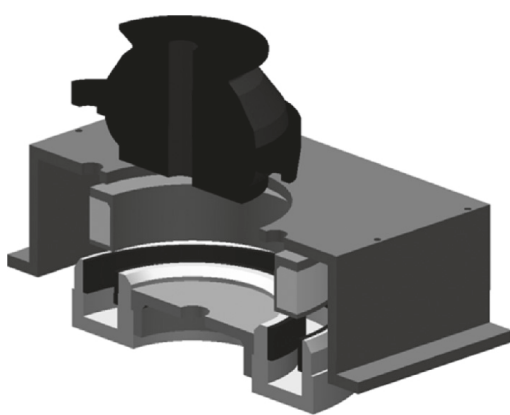

(b)

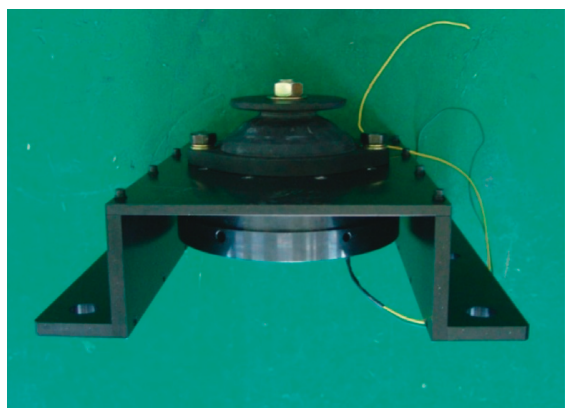

(c)

Figure 9: Assembly of modified electromagnetic actuator. (a) Sectional view. (b) Assembly schematic. (c) Prototype.

the actuator derived from the analysis are summarized in Table 7 .

The sinusoidal input current is applied to the manufactured actuator, and the measured acceleration on the top of mount is shown in Figure 11. Compared with the previous results in Figure 7, it was confirmed that the high frequency or the peripheral frequency component due to the friction had been removed, and the harmonic component was not observed.

In order to examine the satisfaction of the required control force of the proposed electromagnetic actuator, a current which has a sinusoidal waveform of a single frequency is applied, and the force generated at that time is measured by MTS- 810 (material property test machine) and ICP 208C02 (piezo-type force sensor) as shown in Figure 12 and Table 4 . The experimental results are summarized in Figure 13, and the required control force magnitudes for the $26.7 \mathrm{~Hz}$ and $53.4 \mathrm{~Hz}$ target frequency components for the unit current are described in Table 8. It is confirmed that a force greater than the required actuation force for vibration reduction can be generated for the target frequency components. A section where the force rises above $200 \mathrm{~Hz}$ is observed from the experimental results, and it seems that the relatively increased measurement result is obtained due to the ductility effect of the material testing machine structure. 
TABLE 6: Design specification for suggested electromagnetic actuator.

\begin{tabular}{lr}
\hline & Suggested design \\
\hline Electrical gap & $40 \mathrm{~mm}$ \\
Mechanical gap & $2 \mathrm{~mm}$ \\
Coil specification & $\varnothing 1.3 \mathrm{~mm} \times 310$ turns \\
Weight & Abt. $7.2 \mathrm{~kg}$ \\
\hline
\end{tabular}

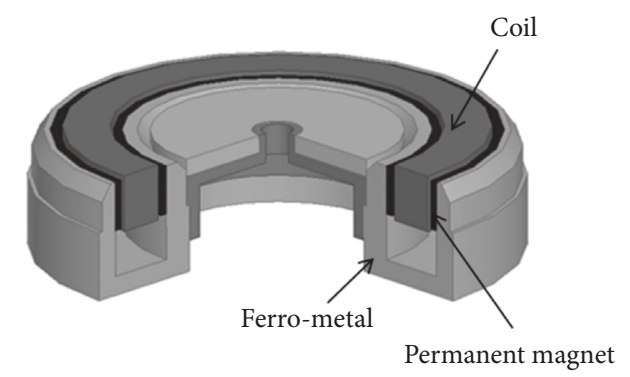

(a)

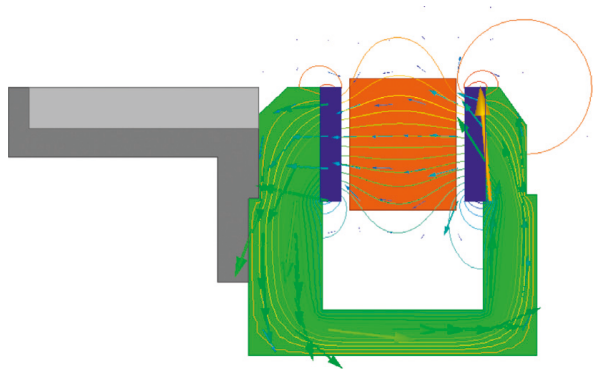

(b)

FIGURE 10: FE analysis of electromagnetic actuator for electromagnetic field by Maxwell. (a) Analysis model. (b) Analysis results of ANSYS Maxwell.

TABLE 7: Major parameters of suggested electromagnetic actuator.

\begin{tabular}{lr}
\hline & Suggested design \\
\hline Resistance & $2.00 \Omega$ \\
Inductance & $0.93 \mathrm{H}$ \\
Input voltage & $150 \mathrm{~V}$ \\
Time constant (L/R) & $0.33 \mathrm{sec}$ \\
\hline
\end{tabular}

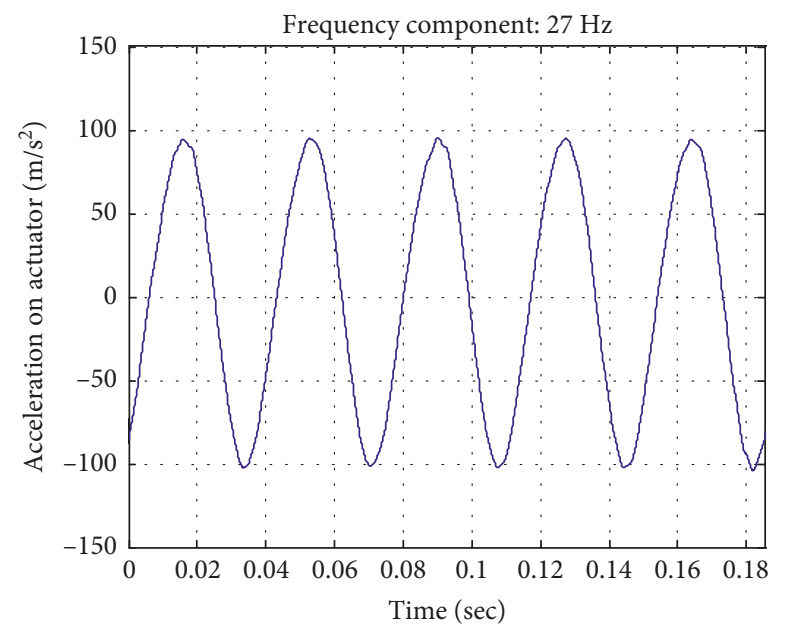

(a)

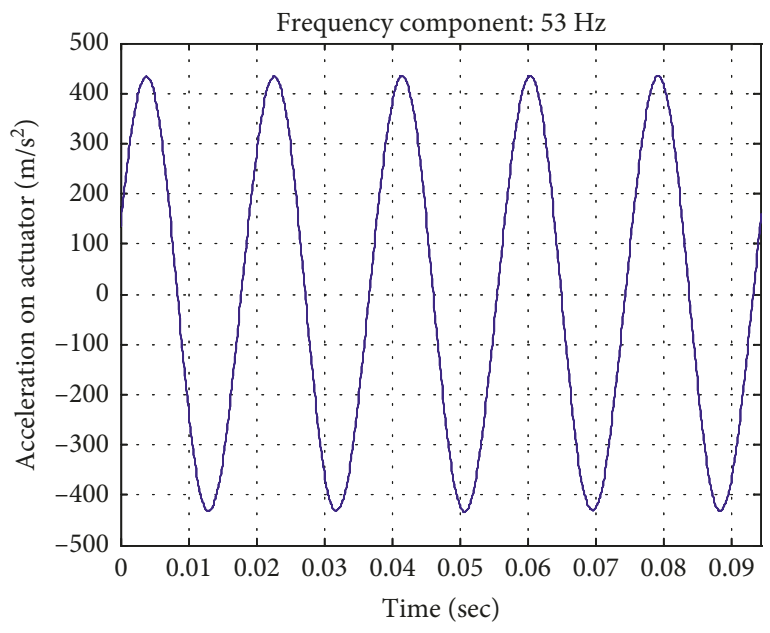

(b)

FIGURE 11: Acceleration of modified actuator for command input voltage of pure sine. (a) $27 \mathrm{~Hz}$. (b) $53 \mathrm{~Hz}$.

\section{Experimental Verification of the Reduction of Transmitted Force by Active Hybrid Mount}

3.1. Application of Control Algorithm to a Simplified 2-DOF System. The effect of applying the Filtered-X LMS algorithm is verified by the simulation of a 2-degree-of-freedom system including the electric field as described in reference [2]. The
Filtered-X LMS algorithm is a kind of adaptive filter that eliminates disturbances by using the reference inputs responsively within the system [10-12]. First, by passing the reference input through a filter whose coefficients are adapted, the convergence and stability of the original LMS algorithm characteristics are dramatically improved, the necessary control force is obtained, and the influence of the 


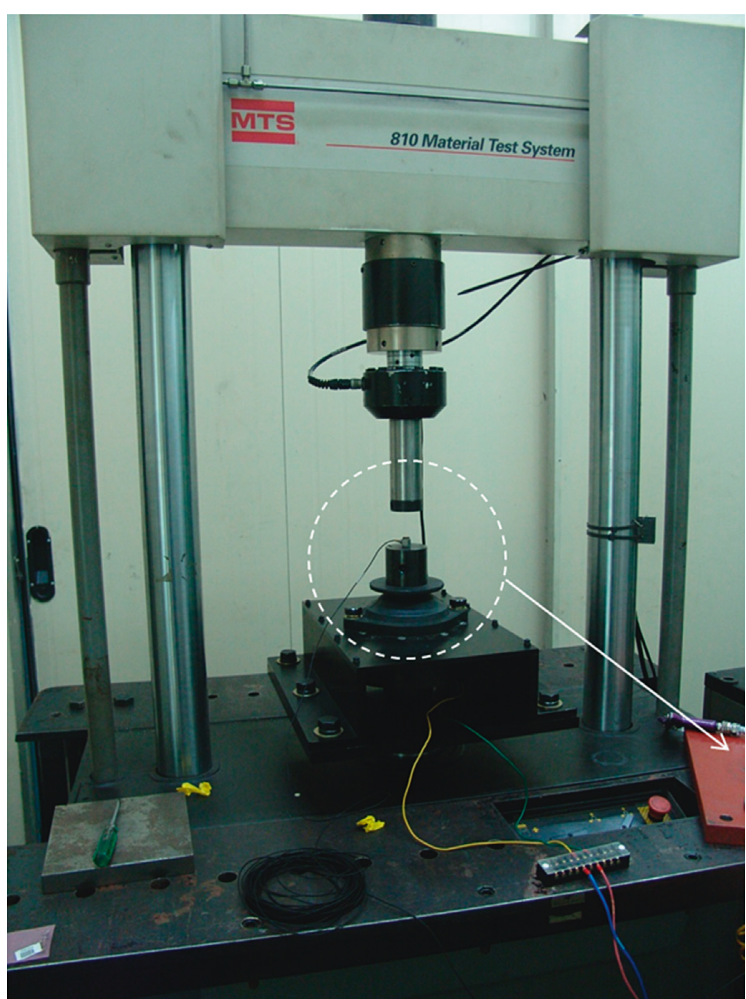

(a)

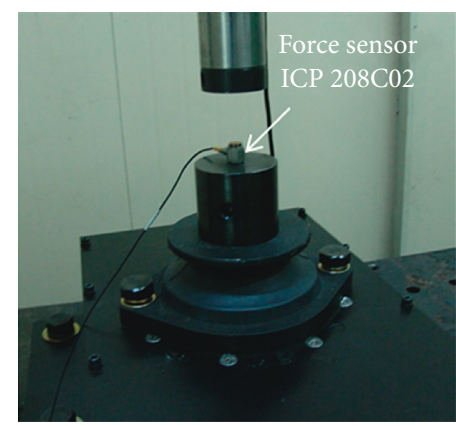

(b)

FigURE 12: Experimental setup for blocking force measurement.

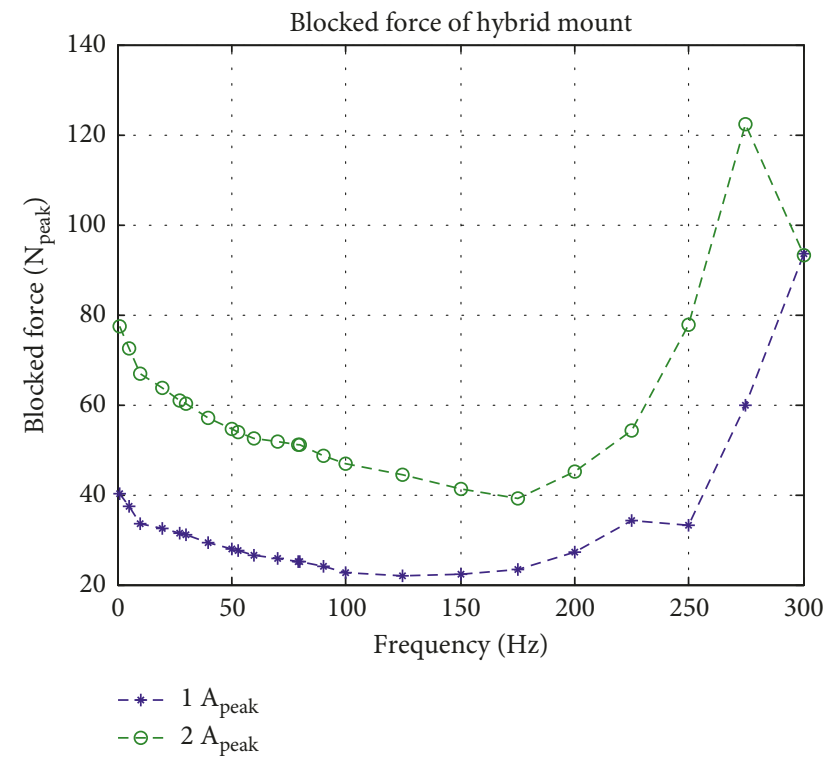

FIGURE 13: Measurement of blocking force for modified electromagnetic actuator.

TABLE 8: Measurement results of blocking force compared with required force.

\begin{tabular}{lcc}
\hline & $26.7 \mathrm{~Hz}$ & $53.4 \mathrm{~Hz}$ \\
\hline Required operating force & $40.3 \mathrm{~N}_{\text {peak }}$ & $3.3 \mathrm{~N}_{\text {peak }}$ \\
Measurement results & $61.0 \mathrm{~N}_{\text {Peak }} @ 2.0 \mathrm{~A}_{\text {Peak }}$ & $53.9 \mathrm{~N}_{\text {Peak }} @ 2.0 \mathrm{~A}_{\text {Peak }}$ \\
Satisfied/not satisfied & Satisfied & Satisfied \\
\hline
\end{tabular}




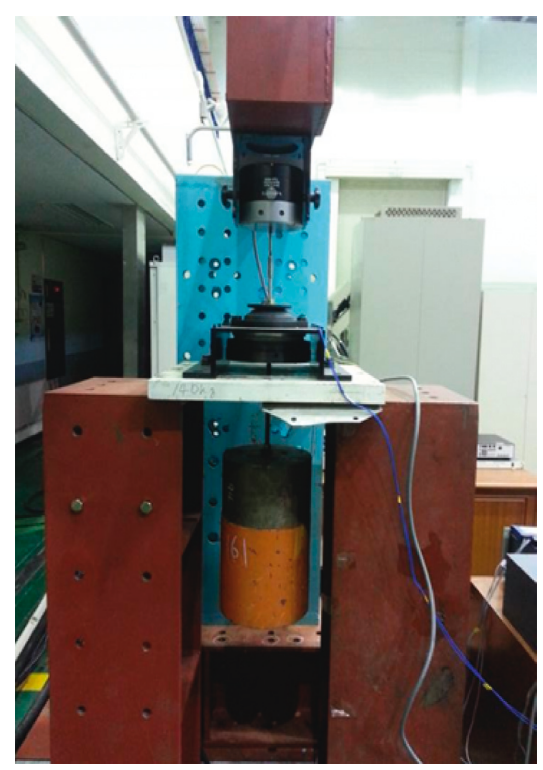

(a)

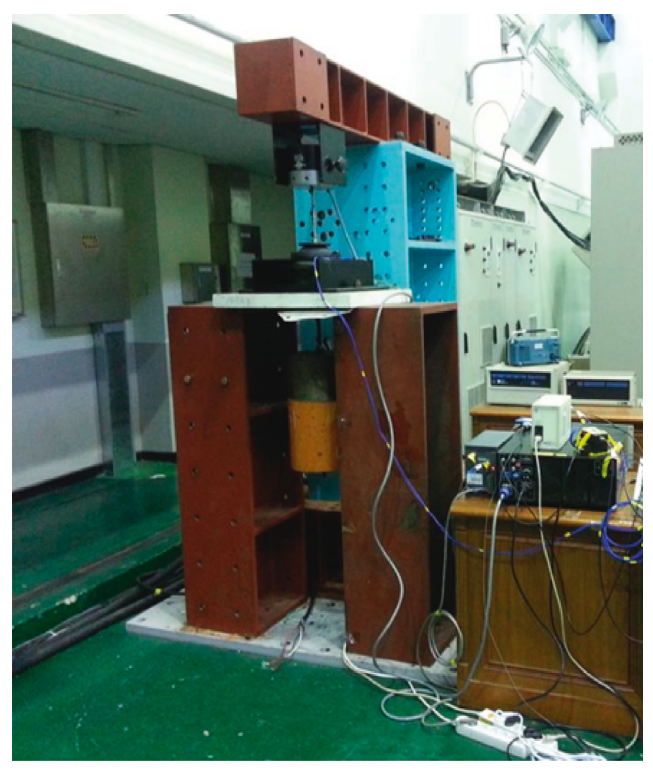

(b)

FIgURE 14: Experimental setup for 2-DOF system with electromagnetic hybrid mount.

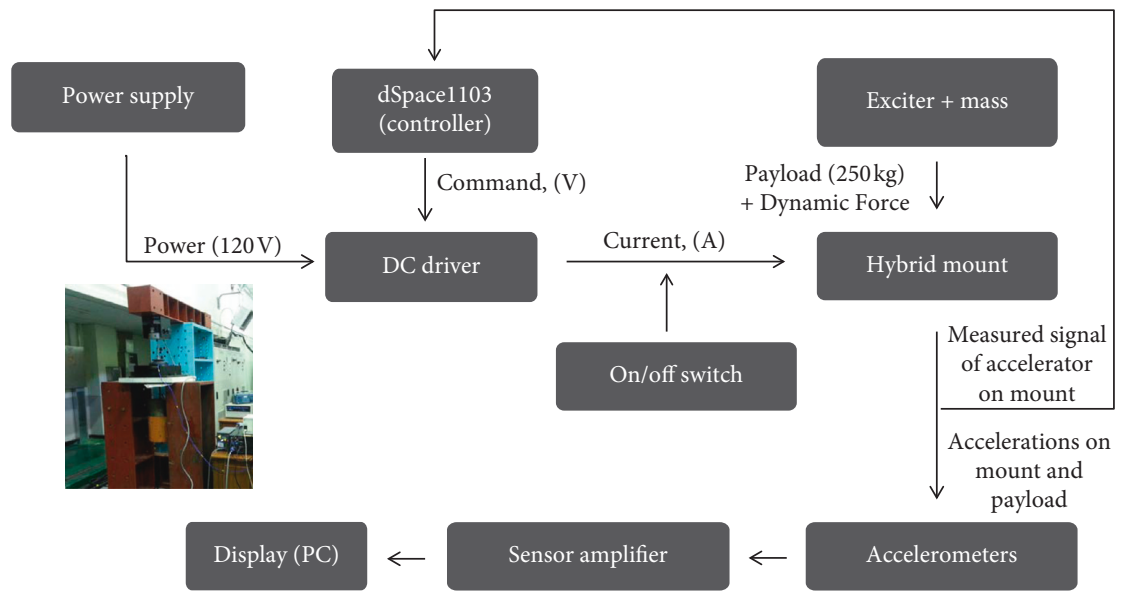

FIgURE 15: Schematic diagram for 2-DOF system with electromagnetic hybrid mount.

disturbance is removed from the system. Because the Filtered-X LMS algorithm uses feedforward control, it is very effective when the frequency characteristics of a target system are known. Finally, experimental apparatus were constructed for the performance test of 2-DOF hybrid mount (electromagnetic actuator) system. A $250 \mathrm{~kg}$ hanging payload is installed so that the center of gravity is low, as shown in Figure 14, and the exciter for generating disturbance is installed directly on the mount. Figure 15 outlines the experimental setup of the final 2-DOF hybrid mount system.

Two kinds of experiments with two different input frequency sets for the Filtered-X LMS algorithm were performed. Both results of 30,60, and $90 \mathrm{~Hz}$ harmonics and 90, 180, and $270 \mathrm{~Hz}$ harmonics all show a reduction of more than $20 \mathrm{~dB}$ as shown in Figure 16, and the effectiveness of the proposed electromagnetic hybrid mount is confirmed. The results are summarized in Table 9.
3.2. Application of Control Algorithm to a 7-DOF System for a Motor System. In addition to the 2-DOF performance test for the hybrid mount (electromagnetic actuator) system, a 7DOF hybrid mount system for confirming the effectiveness of an actual motor system was constructed as shown in Figure 17, and a schematic diagram of the corresponding system in Figure 17(a) is described in Figure 18. An unbalanced mass $(10 \mathrm{~kg})$ was installed at the end of the motor system to implement the driving force of the machine. Four hybrid mounts with electromagnetic actuators were installed supporting four points, and an accelerometer for observing the vibration reduction was attached to the lower end of each mount. Figure 17(b) shows an amplifier, a DC driver, and an analog filter for a 7-DOF system. The control using the Filtered-X LMS algorithm for the target system was implemented by designing and applying an independent controller for each point as shown in Figure 19. The experimental results of a $1,600 \mathrm{rpm}(26.7 \mathrm{~Hz})$ primary 


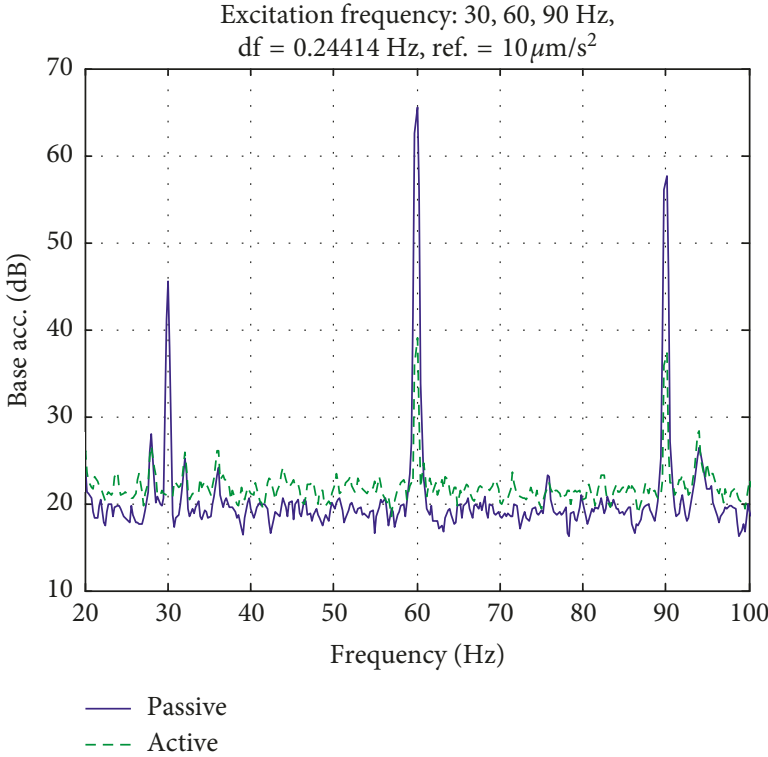

(a)

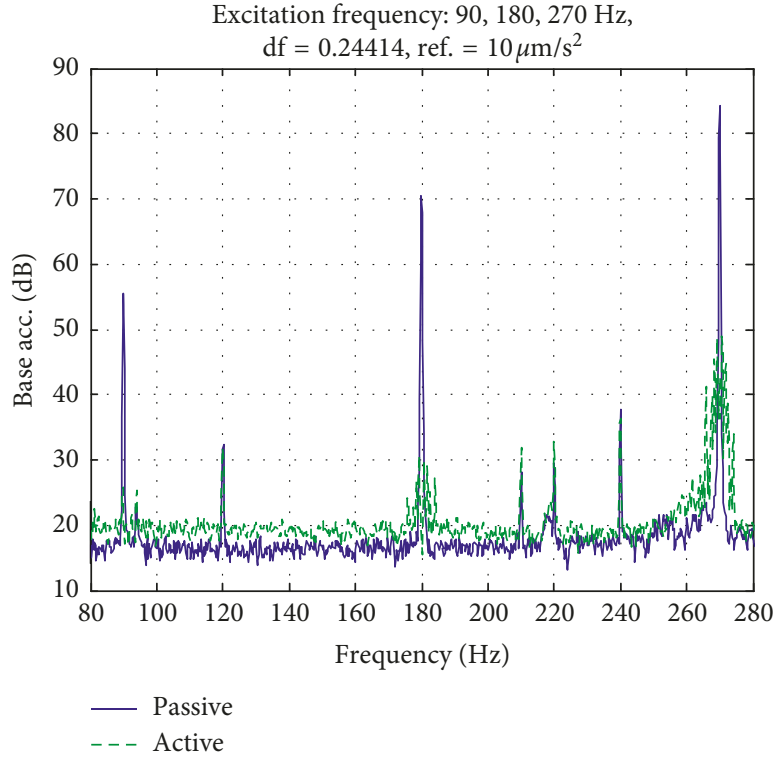

(b)

FigURE 16: Experimental results of vibration reduction while applying hybrid mount. (a) Set \#1: 30, 60, and 90 Hz. (b) Set \#2: 90 , 190, and $270 \mathrm{~Hz}$.

TABLE 9: Measurement results of vibration reduction when applying the hybrid mount.

\begin{tabular}{lcccc}
\hline$\#$ & Frequency $(\mathrm{Hz})$ & Passive $(\mathrm{dB})$ & Active $(\mathrm{dB})$ & Difference $(\mathrm{dB})$ \\
\hline \multirow{3}{*}{ Set \#1 } & $30 \mathrm{~Hz}$ & 45.5 & 20.9 & 24.6 \\
& $60 \mathrm{~Hz}$ & 65.5 & 39.0 & 26.5 \\
\hline \multirow{3}{*}{ Set \#2 } & $90 \mathrm{~Hz}$ & 57.7 & 37.3 & 20.4 \\
& $90 \mathrm{~Hz}$ & 57.5 & 28.0 & 29.5 \\
& $180 \mathrm{~Hz}$ & 72.7 & 32.9 & 39.8 \\
\\
\hline
\end{tabular}
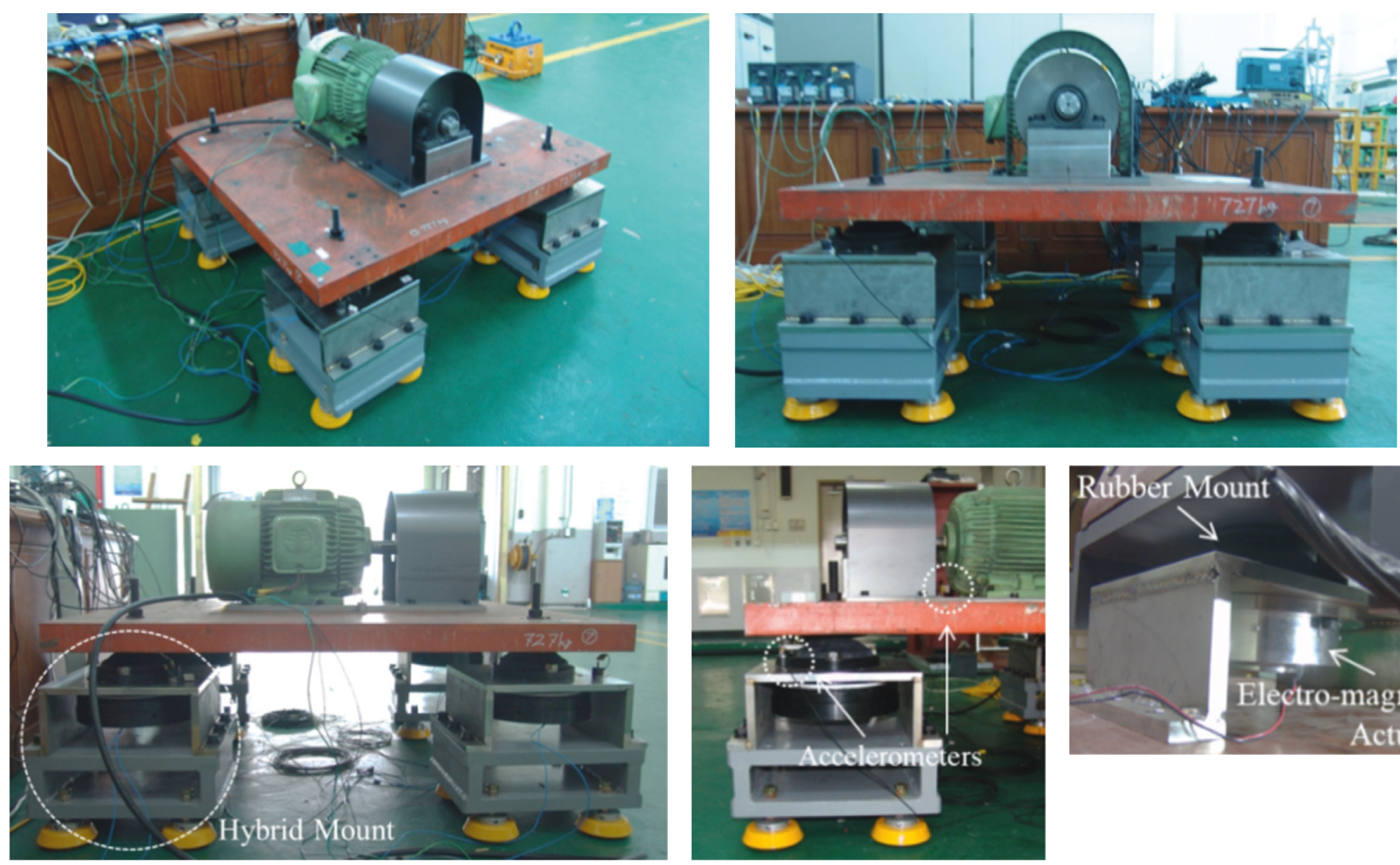

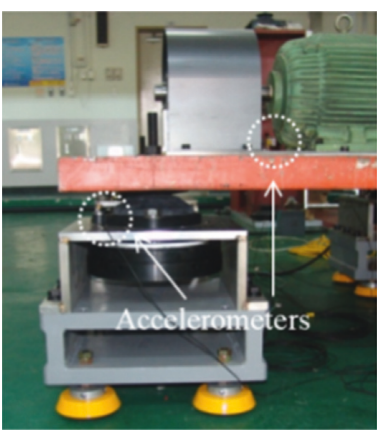

(a)

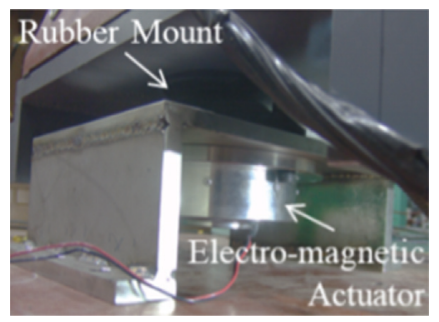

FIgURE 17: Continued. 


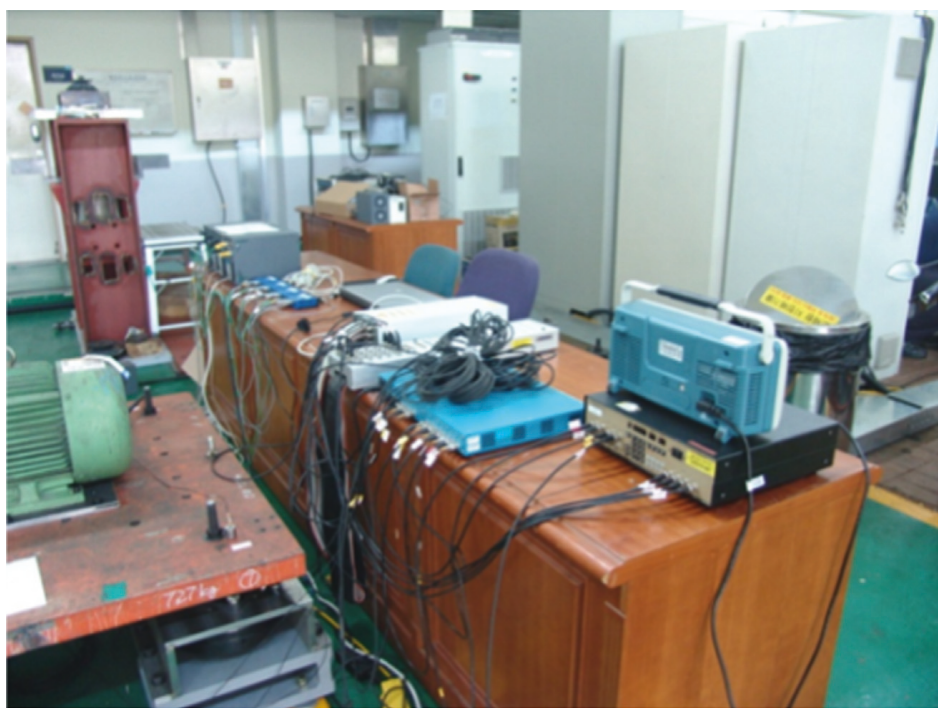

Total controller scheme

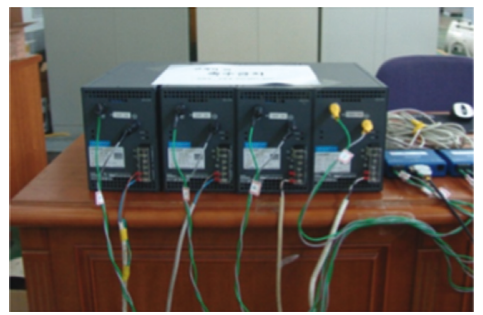

Power suplly

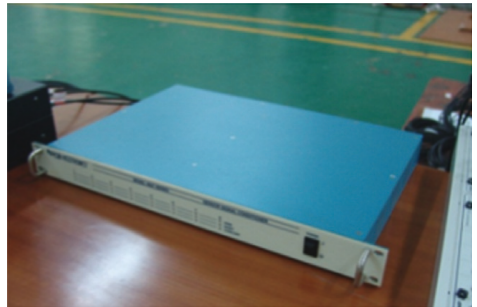

Sensor amp.

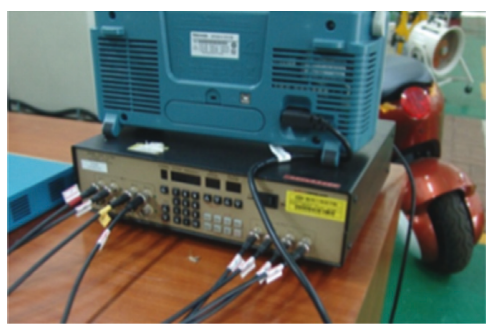

Analog filter

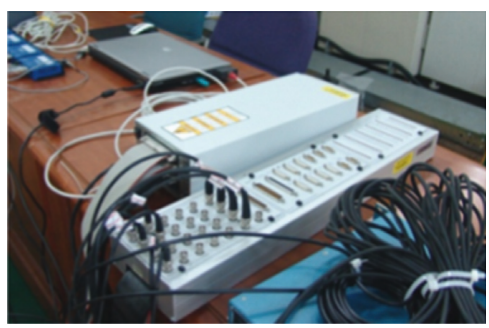

dSpace 1103

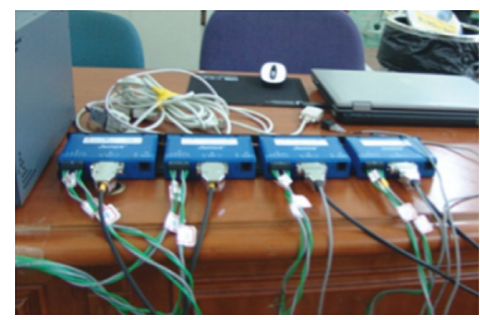

DC driver

(b)

FIGURE 17: Experimental setup for 7-DOF system with electromagnetic hybrid mount. (a) Overall experimental setup for 7-DOF system. (b) Components for control.

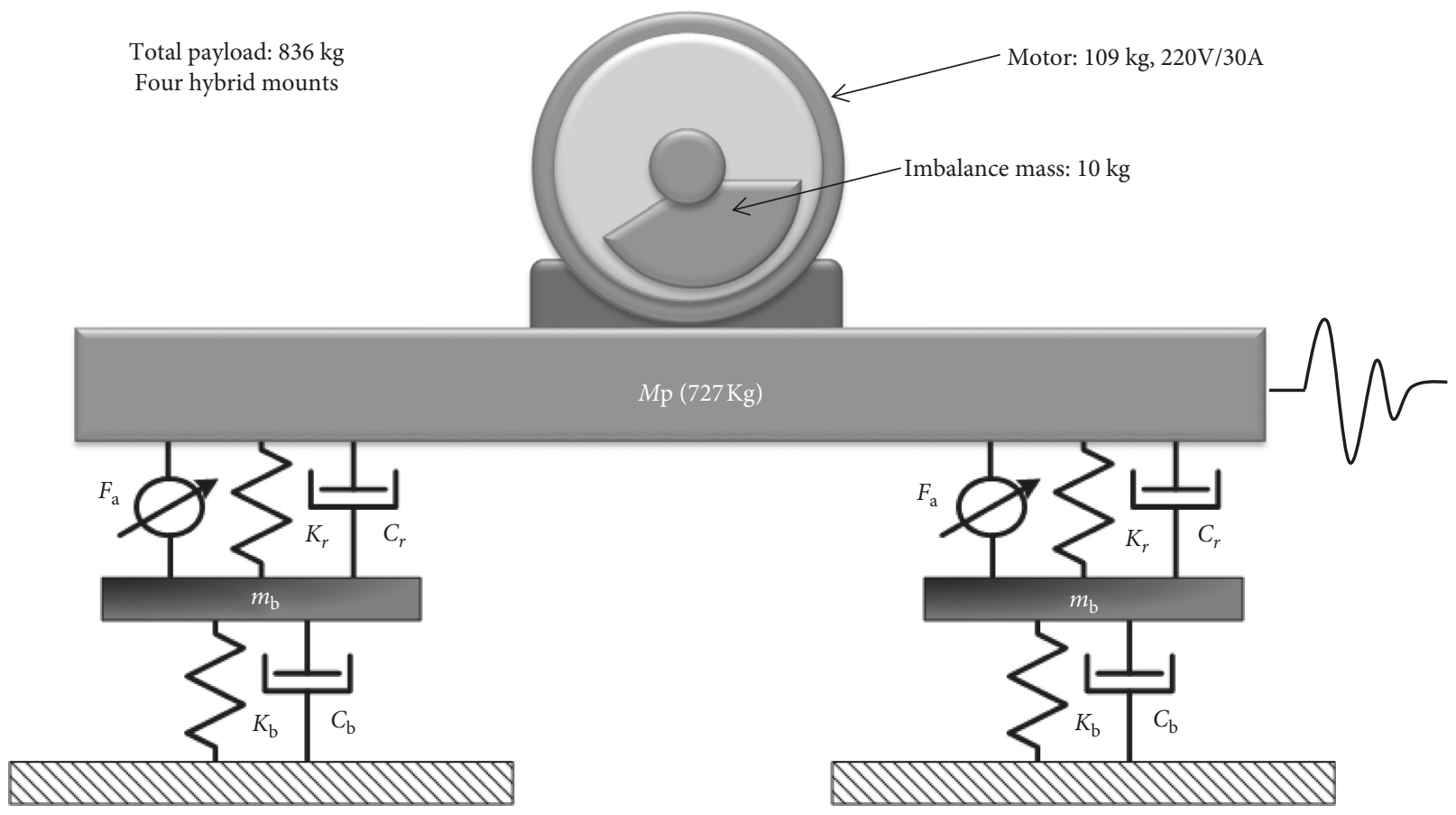

(a)

Figure 18: Continued. 


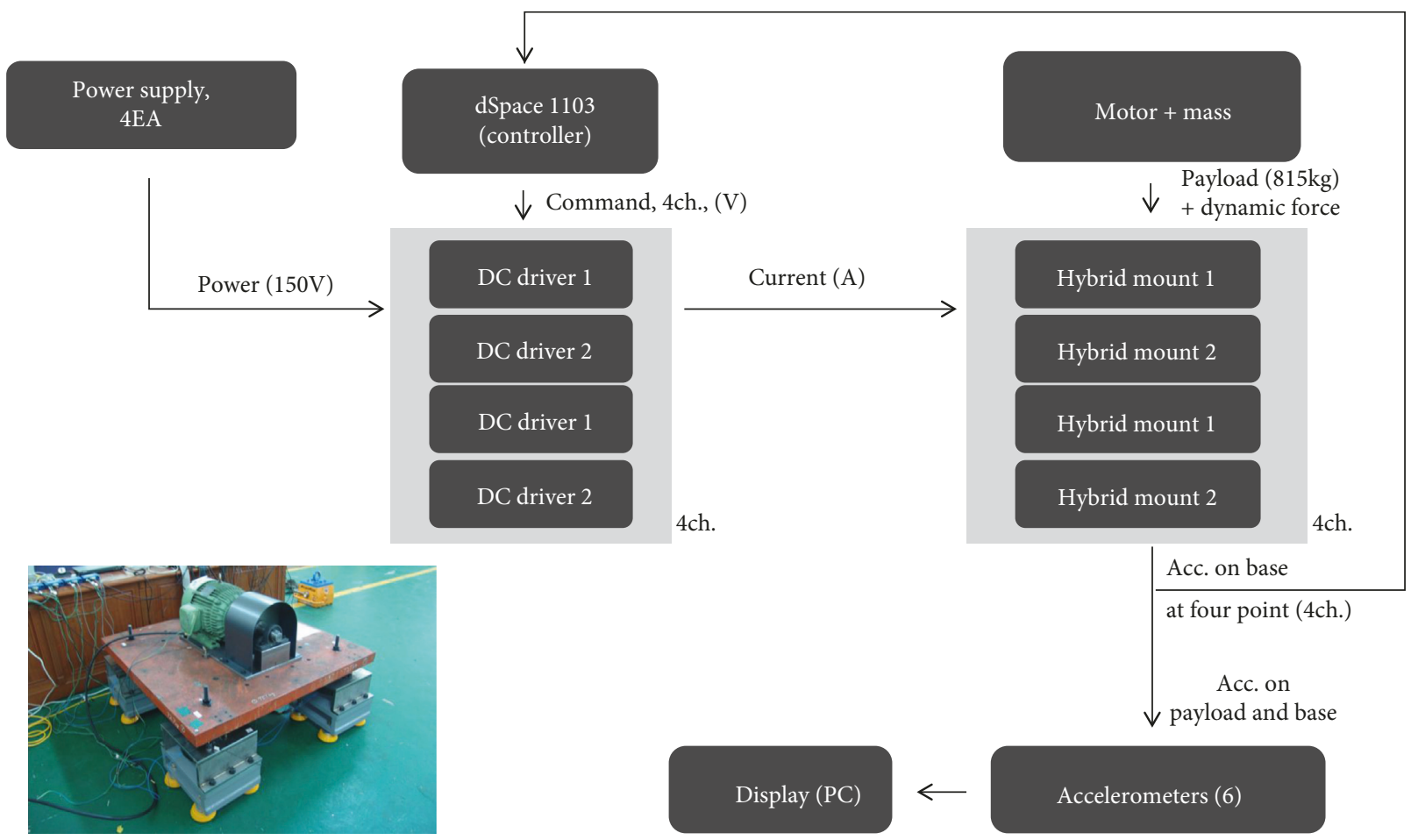

(b)

FIGURE 18: Schematic diagram of the experimental setup for the 7-DOF system. (a) Schematic diagram of the 7-DOF system. (b) Control scheme.

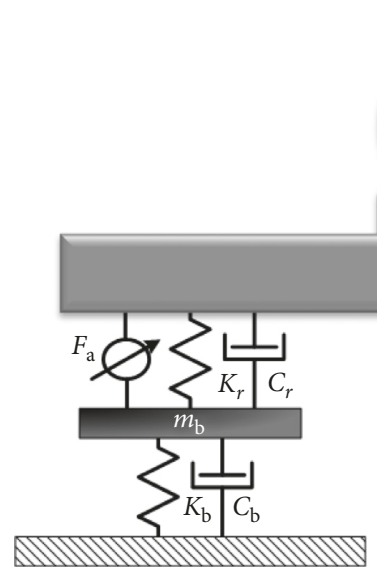

(a)
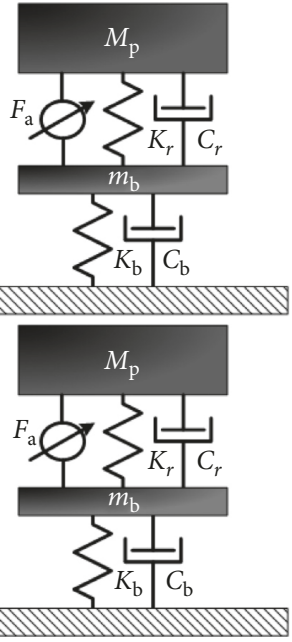

(b)

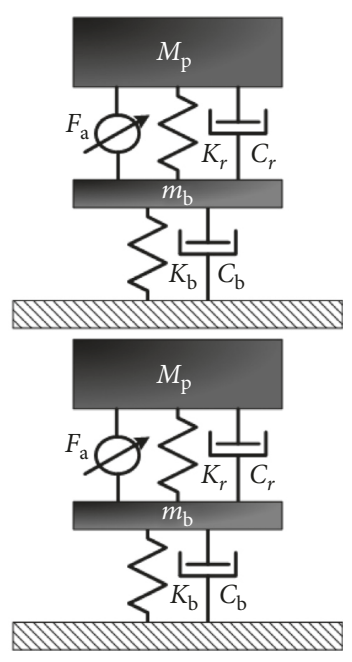

Figure 19: Design schematics of a controller for the 7-DOF system with a hybrid mount. (a) Original system. (b) Control scheme.

component, with consideration of the initial operating frequency and two harmonic components $(53.4 \mathrm{~Hz}$, $80.1 \mathrm{~Hz}$ ), are shown in Figure 20 and Table 10. From the results of applying the proposed electromagnetic hybrid mount, the average vibration reduction of about $19.7 \mathrm{~dB}$ was observed for the excited frequency components.

\section{Conclusion}

An active mount combined with a passive rubber mount and an electromagnetic actuator has been proposed and examined through the rigorous experiment laid out in this paper. It can be applied to naval shipboard equipment. Based on the designs of previous research [2], the electromagnetic actuator was modified and re-suggested in order to improve the performance and overcome its inherent limitations which were caused by the friction between the mover and stator. The design specification of an active mount, such as required force, displacement, and frequency characteristics, was identified for the self-excited pump system, and then an electromagnetic actuator active mount is redesigned with consideration for the shape of the passive rubber mount and 

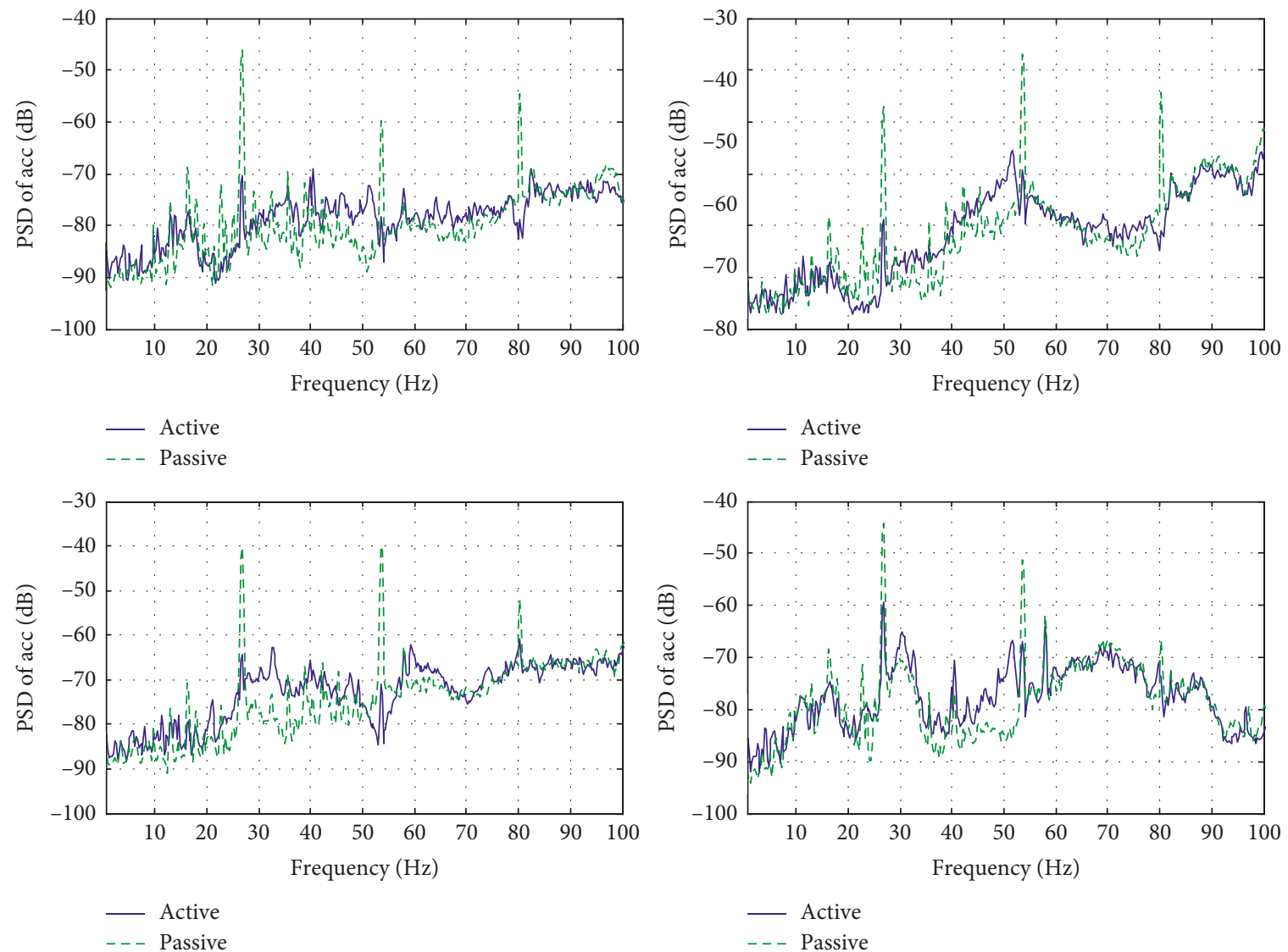

Figure 20: Control results for a 7-DOF system with hybrid mount. (a) Pt. \#1, dB ref $_{1}=1$ g. (b) Pt. \#2, dB ref $_{1}=1$ g. (c) Pt. \#3, dB ref $_{1}=1$ g. (d) Pt. \#4, $\mathrm{dB}_{\text {ref }}=1 \mathrm{~g}$.

TABle 10: Control results for a 7-DOF system with the hybrid mount.

\begin{tabular}{lccccc}
\hline$\#$ & & $26.7 \mathrm{~Hz}$ & $53.4 \mathrm{~Hz}$ & $80.1 \mathrm{~Hz}$ & $\begin{array}{c}\text { Average } \\
(\mathrm{dB})\end{array}$ \\
\hline \multirow{4}{*}{ Point 1 } & Passive & -46.2 & -59.9 & -54.7 & \\
& Active & -70.3 & -78.3 & -79.0 & \\
& Difference & -24.1 & -18.4 & -24.3 & -22.3 \\
\hline \multirow{3}{*}{ Point 2 } & Passive & -47.0 & -36.9 & -44.4 & \\
& Active & -68.9 & -59.4 & -71.2 & \\
& Difference & -21.9 & -22.5 & -26.8 & -23.7 \\
Point 3 & Passive & -40.4 & -39.9 & -51.9 & \\
& Active & -64.4 & -70.9 & -61.0 & \\
& Difference & -20.0 & -31.0 & -9.1 & -20.0 \\
\multirow{2}{*}{ Point 4 } & Passive & -44.1 & -51.2 & -66.8 & \\
& Active & -59.4 & -66.9 & -73.9 & \\
\hline Average $(\mathrm{dB})$ & Difference & -15.3 & -15.7 & -7.1 & -12.7 \\
\hline
\end{tabular}

shock resistance. The performance was examined experimentally on the single active mount using an external exciter and also confirmed experimentally on an active mount system with four mounts using a motor system. From the results of applying the proposed electromagnetic hybrid mount, there was an observed reduction in recorded vibrations to the floor of $23.8 \mathrm{~dB}$ on the single mount system, which is modelled as a 2-DOF system, and $19.7 \mathrm{~dB}$ on the four-mount system, modelled as a 7-DOF system, observed, respectively, for the three harmonic components of vibration.

\section{Data Availability}

The data used to support the findings of this study are available from the corresponding author upon request.

\section{Conflicts of Interest}

The authors declare that they have no conflicts of interest.

\section{Acknowledgments}

This research is a part of the projects that are financially supported by the Korea Institute of Machinery and Materials (project no. NK220D) and Agency for Defense Development of South Korea (contract no. UD110036DD).

\section{References}

[1] A. D. Shaw, S. A. Neild, and D. J. Wagg, "Dynamic analysis of high static low dynamic stiffness vibration isolation mounts," Journal of Sound and Vibration, vol. 332, no. 6, pp. 1437-1455, 2013.

[2] Y.-H. Shin, S.-J. Moon, J.-I. Kwon, W.-J. Jung, and J.-J. Jeon, "A new mount with moving-magnet type electromagnetic actuator for naval shipboard equipment," International 
Journal of Naval Architecture and Ocean Engineering, vol. 7, no. 1, pp. 41-55, 2015.

[3] C.-C. Lan, S.-A. Yang, and Y.-S. Wu, "Design and experiment of a compact quasi-zero-stiffness isolator capable of a wide range of loads," Journal of Sound and Vibration, vol. 333, no. 20, pp. 4843-4858, 2014.

[4] C. Collette, S. Janssens, and K. Artoos, "Review of active vibration isolation strategies," Recent Patents on Mechanical Engineering, vol. 4, no. 3, pp. 212-219, 2011.

[5] H. Y. Cho, S. J. Moon, Y. H. Shin, W. J. Jung, and M. C. Won, "A comparative study on the dynamic characteristics and control performances of hybrid mounts according to element configuration," Transaction on Korean Society for Noise and Vibration Engineering, vol. 22, no. 6, pp. 556-563, 2012.

[6] W. Kaal, T. Bartel, and S. Herold, "Active vibration isolation with a dielectric elastomer stack actuator," Smart Materials and Structures, vol. 26, no. 6, article 055016, 2017.

[7] J. H. Lee, H. Y. Kim, K. H. Kim, M. H. Kim, and S. W. Lee, "Control of a hybrid active-passive vibration isolation system," Journal of Mechanical Science and Technology, vol. 31, no. 12, pp. 5711-5719, 2017.

[8] Military Specification MIL-STD-740-2, Structureborne Vibratory Acceleration Measurements and Acceptance Criteria of Shipboard Equipment, Department of the Navy, Washington, DC, USA, 1986.

[9] Military Specification MIL-S-901D, Shock Tests High Impact Shipboard Machinery Equipment and Systems, Department of the Navy, Washington, DC, USA, 1989.

[10] F. Kerber, S. Hurlebaus, B. M. Beadle, and U. Stobener, "Control concepts for an active vibration isolation system," Mechanical System and Signal Processing, vol. 21, no. 8, pp. 3042-3059, 2007.

[11] B.-H. Lee and C.-W. Lee, "Model based feed-forward control of electromagnetic type active control engine-mount system," Journal of Sound and Vibration, vol. 323, no. 3-5, pp. 574-593, 2009.

[12] B. Widrow and S. D. Stearns, Adaptive Signal Processing, Prentice-Hall, Upper Saddle River, NJ, USA, 1985. 


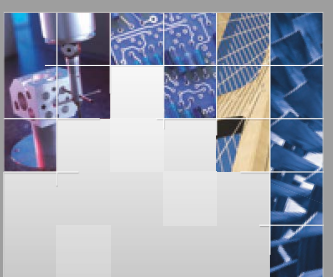

\section{Enfincering}
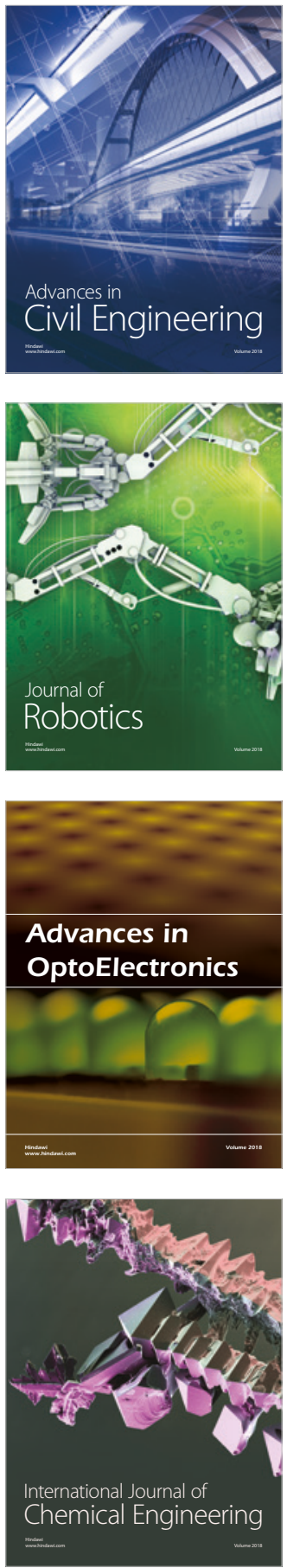

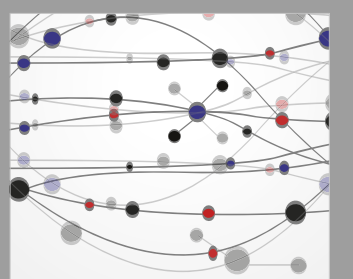

\section{Rotating \\ Machinery}

The Scientific World Journal

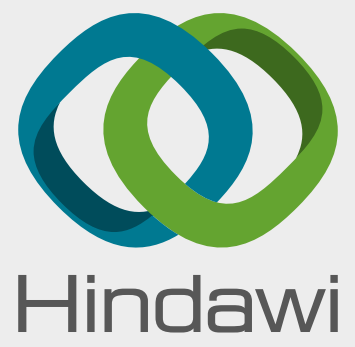

Submit your manuscripts at

www.hindawi.com
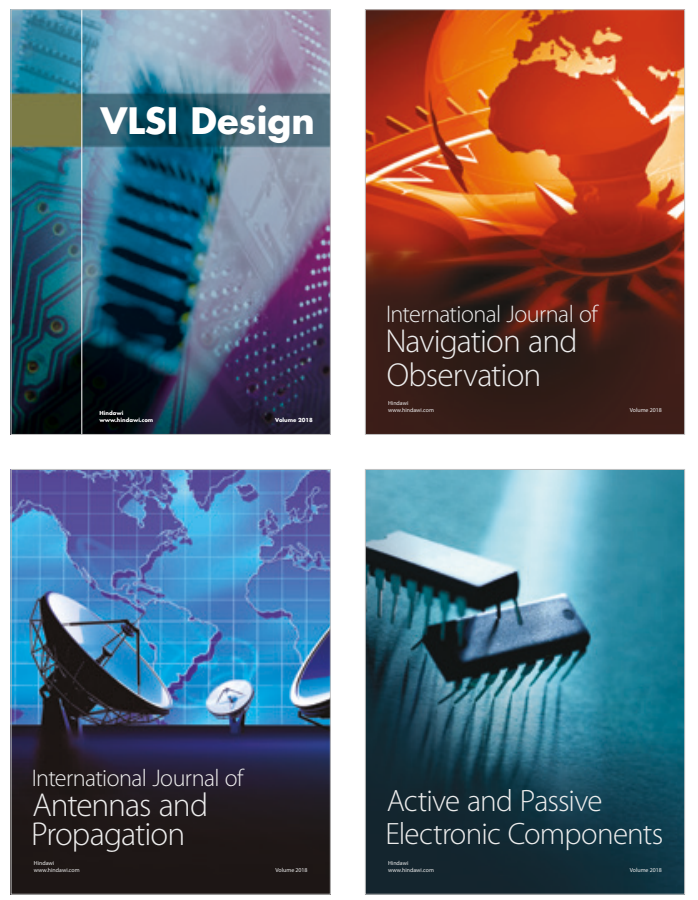
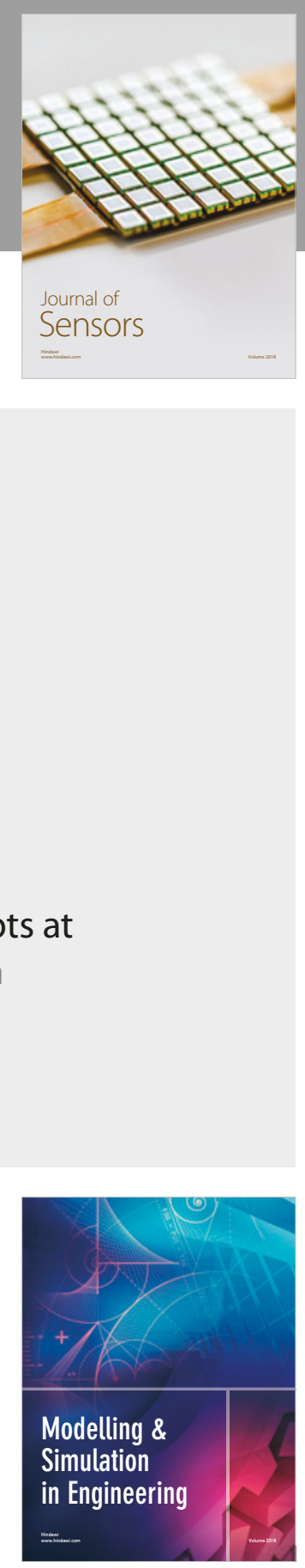

\section{Advances \\ Multimedia}
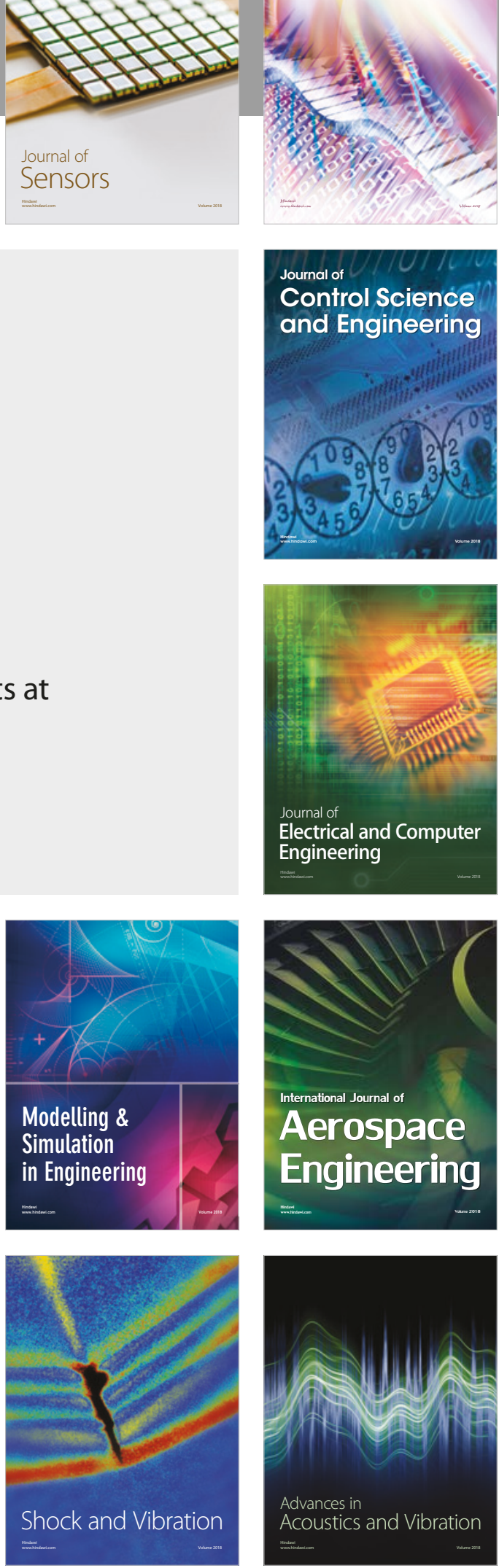